\title{
Potential role of Clostridium difficile as a cause of duodenitis-proximal jejunitis in horses
}

\author{
Correspondence \\ Luis G. Arroyo \\ larroyo@uoguelph.ca
}

Received 17 September 2005

Accepted 27 January 2006

\author{
Luis G. Arroyo, Henry R. Stämpfli and J. Scott Weese \\ Department of Clinical Studies, Ontario Veterinary College, University of Guelph, Guelph, \\ Canada, N1G 2WI
}

\begin{abstract}
Duodenitis-proximal jejunitis (DPJ) is an idiopathic condition in the horse characterized by inflammation and oedema of the duodenum and proximal jejunum. Clinical signs include colic, ileus, depression, fluid accumulation in the small intestine and stomach, and endotoxaemia. The objective of this study was to investigate prospectively the role of Clostridium difficile in this idiopathic disease. Nasogastric reflux from 10 consecutive cases with DPJ and 16 consecutive horses with other causes of nasogastric reflux was cultured for C. difficile, other Clostridium spp., and Salmonella. Toxigenic strains of C. difficile were isolated from 10/10 (100\%) of horses with DPJ and $1 / 16$ controls $(P<0 \cdot 0001)$. No other known pathogenic clostridia were isolated from either group. Results of this study suggest that $C$. difficile might be an important cause of this syndrome.
\end{abstract}

\section{INTRODUCTION}

Duodenitis-proximal jejunitis (DPJ) is an acute sporadic disease in horses, characterized by inflammation and oedema of the duodenum and proximal jejunum. Clinical signs include colic, depression, fluid accumulation in the small intestine and stomach, ileus, and endotoxaemia (Blackwell \& White, 1982; Freeman, 2000). In addition, complications such as cardiac arrhythmias, hepatic injury and laminitis have been reported (Cohen et al., 1994; Cornick \& Seahorn, 1990; Davis et al., 2003).

The initiating cause of this disease remains unknown; however, clostridia, Salmonella spp. and mycotoxins have been suggested elsewhere (Freeman, 2000; Griffiths et al., 1997; Schumacher et al., 1995). Salmonella spp. have been sporadically isolated from the reflux and faeces of horses with clinical signs of DPJ; however, this has been inconsistent and histopathological lesions observed in the small intestine of such cases do not closely resemble those described in salmonellosis (Tyler et al., 1985). Mycotoxins fail to produce clinical disease in experimentally challenged horses, but interestingly it has been reported that the histopathological lesions are similar to those described in DPJ cases (Schumacher et al., 1995). In earlier reports, a clostridial cause was suspected, because a large number of Gram-positive rods were observed on Gram stains of nasogastric reflux samples (White et al., 1987). Additionally, histopathological lesions seen in affected horses are similar to those produced by Clostridium spp. exotoxins (Tyler et al., 1985). However, specific clostridial species cannot

Abbreviation: DPJ, duodenitis-proximal jejunitis. be consistently and repeatedly isolated from affected horses (White et al., 1987; Griffiths et al., 1997).

Clostridium difficile is an important cause of colitis in horses (Jones, 2000; Baverud, 2002); however, its role in DPJ has not been evaluated. Jones et al. (1988) have described severe lesions to the small intestine mucosae of foals naturally infected or following experimental oral challenge with $C$. difficile. Recently, Braun and co-workers have isolated $C$. difficile strains from horses and ponies affected with various small-intestinal disorders (Braun et al., 2000). In humans, small intestinal enteritis with $C$. difficile is not commonly recognized but does occur (Freiler et al., 2001; Elinav et al., 2004). These findings have led to renewed interest in the role of $C$. difficile as a potential cause of DPJ in horses. The objective of this study was to further investigate the hypothesis that clostridia, particularly $C$. difficile, are involved in the pathogenesis of DPJ.

\section{METHODS}

Nasogastric reflux samples. Gastric fluid was collected via nasogastric tube from 10 consecutive clinical cases of DPJ and 16 consecutive horses with other causes of nasogastric reflux admitted to the Ontario Veterinary College-Veterinary Teaching Hospital between January 2004 and August 2005. Horses were diagnosed with DPJ via clinical signs (Freeman, 2000). Control horses were confirmed not to have DPJ via exploratory laparotomy or clinical signs. Samples were collected at the time of admission or within $12 \mathrm{~h}$ of hospitalization. All samples were handled in a blinded manner, stored at $4{ }^{\circ} \mathrm{C}$ and processed within $24 \mathrm{~h}$ of collection.

Culture conditions for Clostridium spp. One to two millilitres of reflux was inoculated into $8 \mathrm{ml}$ non-selective enrichment broth (Brain heart infusion; Oxoid), incubated at $37^{\circ} \mathrm{C}$ for $10-14$ days, and subjected to subculture onto blood agar plates. Plates were 
incubated under anaerobic conditions at $37^{\circ} \mathrm{C}$ for $48 \mathrm{~h}$. Clostridia were identified via colony and Gram-stain morphology, and also using a biochemical system (API strip test; bioMérieux Canada).

Selective enrichment culture for $C$. difficile was performed by the inoculation of 1-2 $\mathrm{ml}$ of reflux into cycloserine-cefoxitin fructose broth enriched with $0 \cdot 1 \%$ sodium taurocholate, and incubated at $37^{\circ} \mathrm{C}$ for $10-14$ days. After incubation, $2 \mathrm{ml}$ was transferred into a sterile test tube, mixed with an equal amount of absolute ethanol and left at room temperature for $60 \mathrm{~min}$. Samples were then centrifuged at $4400 \mathrm{~g}$ for $10 \mathrm{~min}$, the supernatant was discarded, and the resulting pellet was plated onto blood agar and incubated anaerobically at $37^{\circ} \mathrm{C}$ for $48-72$ h. C. difficile was identified via colony characteristics, Gram-stain morphology and production of L-proline aminopeptidase (ProDisc test; Remel, Carr-Scarborough Microbiologicals).

Salmonella culture conditions. One millilitre of reflux was inoculated into $9 \mathrm{ml}$ buffered peptone water and incubated at $35^{\circ} \mathrm{C}$ for $24 \mathrm{~h}$, from which $1 \mathrm{ml}$ was transferred into $9 \mathrm{ml}$ MuellerKaufman tetrathionate broth and incubated under the same conditions. A loopful from the enrichment broth was plated onto XLT agar (Oxoid) and incubated as above for up to $48 \mathrm{~h}$. Colonies suspected to be Salmonella were tested using the BBL Enterotube II, as per the manufacturer's instructions (BD Canada).

DNA extraction. DNA was extracted from $C$. difficile isolates by using a Chelex resin-based DNA extraction kit (InstaGene Matrix; Bio-Rad), as per the manufacturer's instructions.

PCR ribotyping and screening for $C$. difficile genes encoding toxins $\mathbf{A}$ and $\mathbf{B}$, and binary toxin. $C$. difficile isolates were typed by using a PCR ribotyping method, as described elsewhere (Bidet et al., 1999). Isolates were tested for toxigenicity by PCR gene detection of toxin A $(c d t A)$ and toxin $\mathrm{B}(c d t B)$, as well as via testing for the presence of binary toxin (CDT) by amplification of part of the gene encoding the receptor-binding component of this toxin ( $c d t B)$, as described elsewhere (Kato et al., 1998; Stubbs et al., 2000).

Statistical analysis. Categorical analyses were performed using Fisher's exact test. A $P$ value of $<0.05$ was considered significant.

\section{RESULTS}

Toxigenic strains of $C$. difficile were isolated from the nasogastric reflux of $10 / 10(100 \%)$ horses with DPJ, but from only $1 / 16$ of the controls $(P<0 \cdot 0001)$. Seven ribotypes were identified among the 10 isolates, and these ribotypes were indistinguishable from types isolated from horses with $C$. difficile-associated enterocolitis at this teaching hospital (data not shown). Eight of $10(80 \%)$ of the isolates possessed genes encoding the production of both main toxins, toxins $\mathrm{A}$ and $\mathrm{B}$, while two were variant strains that produced toxin B but not toxin A. Additionally, genes encoding binary toxin (CDT) were present in one isolate that also carried the genes encoding toxins $\mathrm{A}$ and $\mathrm{B}$. Three (30\%) horses with DPJ were euthanized, while the remaining seven cases recovered fully. Three of the 10 horses with DPJ developed diarrhoea during hospitalization and $C$. difficile was recovered from their faeces. $C$. difficile toxins were detected in faeces via ELISA in one case, but the other two cases were not tested. One horse required surgical intervention, but the rest responded to medical treatment. All cases that were euthanized were colonized by a variant $\left(\mathrm{A}^{-} \mathrm{B}^{+}\right.$and $\left.\mathrm{A}^{+} \mathrm{B}^{+} \mathrm{CDT}^{+}\right)$strain of $C$. difficile $(P=0 \cdot 008)$.
Clostridium perfringens was isolated from 4/10 DPJ cases and $12 / 16$ controls $(P=0 \cdot 11)$. Salmonella spp. were isolated from the reflux of one horse in the control group but not from horses with DPJ $(P=1 \cdot 0)$.

\section{DISCUSSION}

The strong association of the presence of toxigenic strains of $C$. difficile in gastric reflux from horses with DPJ is an important finding that suggests an aetiology for this previously idiopathic disease. While DPJ is a condition of the small intestine, it is reasonable to assume that gastric fluid analysis can be useful because of the tendency for excessive fluid production and decreased aboral intestinal motility to result in reflux of small intestinal fluid into the stomach. The low prevalence of $C$. difficile in gastric fluid from horses with other conditions that result in the flow of small intestinal fluid into the stomach (i.e. small intestinal obstructions) suggests that isolation of $C$. difficile from gastric fluid of horses with DPJ does not simply represent backflow of commensal $C$. difficile from the small intestine.

Ileus and fluid accumulation in the small intestine and stomach lumen, prominent characteristics of DPJ, have also been reported in some humans and in laboratory animals with C. difficile infection (Perkings et al., 1995; Siemann et al., 2000; Freiler et al., 2001; Elinav et al., 2004). In vitro experiments have shown that $C$. difficile toxin B causes electromechanical disturbances to the small intestine smooth muscle (Gilbert et al., 1989). These observations suggest that $C$. difficile toxins may play an important role in the gastrointestinal motility of humans or animals suffering from $C$. difficile-associated enterocolitis. These factors support the implication of $C$. difficile in DPJ.

The timing of sample collection, the diverse geographical origin of the cases and molecular type diversity of the isolates may suggest that the strains were of community origin. However, this observation requires further molecular epidemiological studies. Contrary to the common situation in humans, in which most of the cases are nosocomial in origin (Barbut \& Petit, 2001; Riley, 2004), most C. difficileassociated infection in horses appears to be community associated (Baverud, 2004). The reasons for development of DPJ versus colitis are unclear and require further investigation; however, the fact that isolates recovered from horses with DPJ were comparable to isolates commonly identified in horses with colitis suggest that specific $C$. difficile DPJ strains are not the reason.

The proportion of toxin variants was surprising, particularly the strains possessing genes for toxin B but not toxin A $\left(\mathrm{A}^{-} \mathrm{B}^{+}\right)$. These variant strains are not commonly identified in humans (Brazier et al., 1999), but may be more common in some animals (Rodriguez et al., 2005). One C. difficile isolate carried the gene encoding binary toxin and was recovered from a horse with severe clinical signs of DPJ. The clinical significance of the binary toxin (CDT) in humans and animals remains currently unknown, but it is 
expected that this toxin constitutes an additional virulence factor (Rupnik et al., 2003; Geric et al., 2004; Barbut et al., 2005).

The isolation of $C$. perfringens from DPJ cases and control horses is in agreement with previous reports (Griffiths et al., 1997), and does not indicate an association between $C$. perfringens and DPJ. Similarly, there was no evidence that Salmonella was associated with DPJ, as it was not isolated from the reflux of any DPJ cases, which is in agreement with reports elsewhere (White et al., 1987; Griffiths et al., 1997). In our study, cultures for Salmonella were performed on a single reflux sample; therefore, intermittent shedding could not be discounted. However, the strong association of $C$. difficile with DPJ and the results of other studies evaluating Salmonella in DPJ make it unlikely that Salmonella is an important cause of this disease.

The results of the present study suggest that $C$. difficile has a role as a cause of DPJ in horses. The isolation of $C$. difficile from the reflux of horses with DPJ does not prove causation, but indicates that further investigation of the potential role of this pathogen by means of a larger prospective study is indicated. Further, associated risk factors that ultimately may favour bacterial growth and toxin production also need to be determined. Recently, Cohen and co-workers have found that horses kept on pasture or fed high amounts of concentrate diets appear to be at higher risk of developing this disease (Cohen et al., 2005). This presumably could be associated with disruption of the intestinal microflora, thereby facilitating colonization and overgrowth of $C$. difficile. The reasons for development of DPJ versus colitis also require further study.

\section{ACKNOWLEDGEMENTS}

This project was not supported by any funding, granting agency or institution. This information was presented in part as an abstract (poster) at the 23rd Annual American College of Veterinary Internal Medicine Conference, June 1-4 2005, Baltimore, MD, and as an oral abstract at the 8th Equine Colic Research Symposium, August 3-5 2005, Quebec City, Canada.

\section{REFERENCES}

Barbut, F. \& Petit, J. C. (2001). Epidemiology of Clostridium difficileassociated infections. Clin Microbiol Infect 7, 405-410.

Barbut, F., Decré, D., Lalande, V. \& 9 other authors (2005). Clinical features of Clostridium difficile-associated diarrhoea due to binary toxin (actin-specific ADP-ribosyltransferase)-producing strains. J Med Microbiol 54, 181-185.

Baverud, v. (2002). Clostridium difficile infections in animals with special reference to the horse. A review. Vet Q 24, 203-219.

Baverud, V. (2004). Clostridium difficile diarrhea: infection control in horses. Vet Clin North Am Equine Pract 20, 615-630.

Bidet, P., Barbut, F., Lalande, V., Burghoffer, B. \& Petit, J. C. (1999). Development of a new PCR-ribotyping method for Clostridium difficile based on ribosomal RNA gene sequencing. FEMS Microbiol Lett 175, 261-266.
Blackwell, R. B. \& White, N. A. (1982). Duodenitis/proximal jejunitis in the horse. In Proceedings of the Equine Colic Research Symposium, vol. 1. Athens, GA: College of Veterinary Medicine, University of Georgia.

Braun, M., Herholz, C., Straub, R., Choisat, B., Frey, J., Nicolet, J. \& Kunert, P. (2000). Detection of the ADP-ribosyltransferase toxin gene $(c d t A)$ and its activity in Clostridium difficile isolates from Equidae. FEMS Microbiol Lett 184, 29-33.

Brazier, J. S., Stubbs, S. L. \& Duerden, B. I. (1999). Prevalence of toxin A negative/B positive Clostridium difficile strains. J Hosp Infect 42, 248-249.

Cohen, N. D., Parson, E. M., Seahorn, T. L. \& Carter, G. K. (1994). Prevalence and factors associated with development of laminitis in horses with duodenitis/proximal jejunitis: 33 cases (1985-1991). J Am Vet Med Assoc 204, 250-254.

Cohen, N., Murphy, E., Roussell, A., Minor, M., Payne, M. \& Payne, F. (2005). Is duodenitis-proximal jejunitis associated with high concentrate diets? In Proceedings of the Equine Colic Research Symposium, vol. 1. Lexington, KY: AAEP Foundation.

Cornick, J. L. \& Seahorn, T. L. (1990). Cardiac arrhythmias identified in horses with duodenitis/proximal jejunitis: six cases (1985-1988). J Am Vet Med Assoc 197, 1054-1059.

Davis, J. L., Blikslager, A. T., Catto, K. \& Jones, S. L. (2003). A retrospective analysis of hepatic injury in horses with proximal enteritis (1984-2002). J Vet Intern Med 17, 896-901.

Elinav, E., Planer, D. \& Gatt, M. E. (2004). Prolonged ileus as a sole manifestation of pseudomembranous enterocolitis. Int $J$ Colorectal Dis 19, 273-276.

Freeman, D. E. (2000). Duodenitis-proximal jenunitis. Equine Vet Educ 12, 322-332.

Freiler, J. F., Durning, J. S. \& Ender, P. T. (2001). Clostridium difficile small bowel enteritis occurring after total colectomy. Clin Infect Dis 33, 1429-1431.

Geric, B., Rupnik, M., Gerging, D. N., Grabnar, M. \& Johnson, S. (2004). Distribution of Clostridium difficile variant toxinotypes and strains with binary toxin genes among clinical isolates in an American hospital. J Med Microbiol 53, 887-894.

Gilbert, R. J., Pothoulakis, C. \& LaMont, J. T. (1989). Effect of purified Clostridium difficile toxins on intestinal smooth muscle. II. Toxin B. Am J Physiol 256, 767-772.

Griffiths, N. J., Walton, J. R. \& Edwards, G. B. (1997). An investigation of the toxigenic types of Clostridium perfringens in horses with anterior enteritis: preliminary results. Anaerobe 3, 121-125.

Jones, R. L. (2000). Clostridial enterocolitis. Vet Clin North Am Equine Pract 16, 471-485.

Jones, R. L., Shideler, R. K. \& Cockerell, G. L. (1988). Association of Clostridium difficile with foal's diarrhea. In Equine Infectious Disease $V$, pp. 236-240. Lexington, KY: University Press of Kentucky.

Kato, H., Kato, N., Watanabe, K. \& 7 other authors (1998). Identification of toxin A-negative, toxin B-positive Clostridium difficile by PCR. J Clin Microbiol 36, 2178-2182.

Perkings, S. E., Fox, J. G., Taylor, N. S., Green, D. L. \& Lipman, N. S. (1995). Detection of Clostridium difficile toxins from the small intestine and cecum of rabbits with naturally acquired enterotoxemia. Lab Anim Sci 45, 379-384.

Riley, T. V. (2004). Nosocomial diarrhoea due to Clostridium difficile. Curr Opin Infect Dis 17, 323-327.

Rodriguez, A., Staempfli, H., Duffield, T., Peregrine, A., TrotzWilliams, L., Arroyo, L. G. \& Weese, J. S. (2005). Role of Clostridium difficile in neonatal calf diarrhea: a blinded paired case-control study in dairy calves. J Vet Intern Med 19, 299. 
Rupnik, M., Grabnar, M. \& Geric, B. (2003). Binary toxin producing Clostridium difficile strains. Anaerobe 9, 289-294.

Schumacher, J., Mullen, J., Shelby, R., Lenz, S., Ruffin, D. C. \& Kemppainen, B. W. (1995). An investigation of the role of Fusarium moniliforme in duodenitis/proximal jejunitis of horses. Vet Hum Toxicol 37, 39-45.

Siemann, M., Koch-Dorfler, M. \& Rabenhorst, G. (2000). Clostridium difficile-associated diseases. Intensive Care Med 26, 416-421.

Stubbs, S., Rupnik, M., Gibert, M., Brazier, J., Duerden, B. \& Popoff, M. (2000). Production of actin-specific ADP-ribosyltransferase (binary toxin) by strains of Clostridium difficile. FEMS Microbiol Lett 186, 307-312.

Tyler, D. E., White, N. A., Blackwell, R. B. \& Allen, D. (1985). Pathology of equine duodenitis-proximal jejunitis (anterior enteritis). In Proceedings of the Equine Colic Research Symposium, vol. 2. Lawrenceville, NJ: Veterinary Learning Systems.

White, N. A., II, Tyler, D. E., Blackwell, R. B. \& Allen, D. (1987). Hemorrhagic fibrinonecrotic duodenitis-proximal jejunitis in horses: 20 cases (1977-1984). J Am Vet Med Assoc 190, 311-315. 